\title{
UV kürlenmeli vernik uygulanmış sedir odununun yapay yaşlandırma uygulaması sonrasında bazı yüzey özelliklerinin belirlenmesi
}

\author{
Ümit Ayata $^{1 *(D)}$, Nevzat Çakıcıer ${ }^{2}$, Levent Gürleyen ${ }^{3}$ (D)
}

\section{$\ddot{\mathbf{O z}}$}

UV kürlenmeli uygulamaların kullanımları, günümüzde teknolojinin gelişmesi ile yaygın bir hale gelmiştir. Bu UV kürlenmeli sistemlerin avantajları da, müşterilerin kullanıma ait çeşitli özelliklerini (uçucu organik bileşik, direnç, vb.) desteklemektedir. Bu uygulamalar birçok sektör açısından tercih edilmekte olunup, uygulama alanlarından biriside ahşap malzeme yüzeyleri olmaktadır. Bu çalışmada, endüstriyel uygulamalara göre Toros sediri (Cedrus libani A. Rich) odunu yüzeylerine UV kürlenmeli parke vernikleri uygulanmış malzemeler üzerinde UV-B 313 lambalarının bulunduğu yapay yaşlandırmaya ortamına maruz bırakılması ile meydana gelen yüzeylerdeki değişiklikler araştırılmıştır. Araştırma sonuçlarına göre; yaşlandırma uygulamaları, parlaklık $\left(20^{\circ}, 60^{\circ}\right.$ ve $85^{\circ}$ de liflere paralel ve dik) değerlerinde ve 1 șıklılık $\left(L^{*}\right)$ değerlerinde azalmalara, kırmızı $\left(a^{*}\right)$ ve sarı $\left(b^{*}\right)$ renk ton değerlerinde ise artışlar görülmüştür. Buna ek olarak, salınımsal sertlik değerleri 3 kat uygulamada yaşlandırma sonrasında azalırken, 5 kat uygulamasında artmıştır. 504 saatlik yaşlandırma sonunda her iki vernik türünde toplam renk farkı $\left(\Delta E^{*}\right)$ değerleri "farklı renk" kriterini vermiştir. Sonuç olarak, literatürdeki çalışmalarla kıyaslandığında Toros sedirinin UV sistem parke endüstrisinde kullanılabileceği söylenebilir.

Anahtar kelimeler: Toros sediri, yaşlandırma, UV vernik, renk, salınımsal sertlik

\section{Determination of some surface properties of UV curable varnish-applied cedar wood after artificial aging application}

\begin{abstract}
The use of UV curing applications has become widespread with the development of technology today. The advantages of these UV curable systems also support customers' various usage characteristics (volatile organic compound, resistance, etc.). These applications are preferred in terms of many sectors, and one of the application areas is wood material surfaces. In this study, changes in the surfaces of Taurus cedar (Cedrus libani A. Rich) wood surfaces, which are exposed to artificial aging environment with UV-B 313 lamps, on materials with UV curing parquet varnishes were investigated according to industrial applications. According to the research results; aging applications, brightness (parallel and perpendicular to the fibers at $20^{\circ}, 60^{\circ}$ and $85^{\circ}$ ) values and luminance $\left(L^{*}\right)$ values decreased, while red $\left(a^{*}\right)$ and yellow $\left(b^{*}\right)$ color tone values increased. In addition, the pendulum hardness values decreased after aging in the 3-coat application and increased in the 5-coat application. After 504 hours of aging, the total color difference $\left(\Delta E^{*}\right)$ values in both varnish types gave the "different color" criterion. As a result, it can be said that Taurus cedar can be used in the UV system parquet industry when compared with the studies in the literature.
\end{abstract}

Keywords: Taurus cedar, aging, UV varnish, color, pendulum hardness 


\section{Giriş}

Ahşabın yüzeyi, herhangi bir koruma olmaksızın çevreye maruz kaldığında nispeten daha hızı bozulmaktadır (Evans ve ark., 1996). Güneş 1şığının (özellikle UV ve görünür ışık) ve suyun (yağmur ve doğal nem) diş mekân maruziyeti sırasında ahşap yüzeye zarar veren en yaygın unsurlar olduğu iyi bilinmektedir (Hon, 2001; Can, 2018).

Organik bir kaplamanın dayanıklılığı, hizmet ömrü boyunca maruz kaldığı doğal ortamın neden olduğu istenmeyen değişikliklere karşı gösterdiği direnç olarak tanımlanabilir (Gheno ve ark., 2016).

Radyasyonla kürlenebilen kaplama teknolojisi son zamanlarda önemli ilerlemeler kaydetmiş ve bilimsel ve endüstriyel alanlarda büyük ilgi görmüştür (Wicks, 2007). Ultraviyole (UV) ile kürlenebilen kaplamalar, aktif bileşimlerin polimerizasyonunu indükleyen UV 1şıması ile çok kısa sürede kürlenebilir. Bu kaplamaların formülasyonları, foto başlatıcı, monomer, reaktif seyreltici ve diğer yardımcı katkı maddelerinden oluşmaktadır (Liu ve ark., 2020). Bu kaplamalar, hiç veya çok az uçucu organik bileşiklere sahip bir kaplama sınıfıdır. Bu tip kaplamalar, geniş formülasyon yelpazesi, daha az enerji tüketimi, anında kuruma, ısıya duyarlı alt tabakayı kaplayabilme ve düşük alan gibi birçok avantaj sunar. Bu kaplamaların ek avantajı, ortam sıcaklığında çok hızlı bir kürlenme sağlar (Bruen ve ark., 2004; Chiang ve Chan, 1987) ve foto başlatıcılar tarafından başlatılan ve daha sonra çapraz bağlanan bir tür çevre dostu polimerdir (Kilambi ve ark., 2014; Pedrón ve ark., 2008).

Yapılan literatür araştırmalarının incelenmesi sonucunda Toros sediri odunu yüzeylerine herhangi bir UV sistem kimyasallarının (vernik, boya, vb.) uygulanmadığ görülmektedir.

Toros sediri (Cedrus libani A. Rich) günümüzde Türkiye, Suriye ve Lübnan dağlarında deniz seviyesinden 1.400 ila 2.200 m yükseklikte bulunmaktadır (Dutkuner ve Akten, 2000). Ahşabı, dayanıklılığı, yoğunluğu, rengi, kerestesi ve böcek ilacı özellikleri nedeniyle eski zamanlardan beri büyük beğeni toplamıştır. Orta Doğu'daki kraliyet mezarları için bir seçim kerestesi olduğu bildirilmiştir (Rogers ve Kaya, 2006). Toros sediri odununda tam kuru yoğunluk $497.00 \mathrm{~kg} / \mathrm{m}^{3}$, hava kurusu yoğunluk $517.00 \mathrm{~kg} / \mathrm{m}^{3}$, teğet genişleme $\% 6.40$, radyal genişleme $\% 4.00$, boyuna genişleme $\% 0.20$, hacmen genişleme $\% 10.60$, genişleme anizotropisi 1.66, lif doygunluk noktası $\% 21.30$, iki hafta sonunda aldığı su miktarı \%80.70, vida tutma direnci teğet yüzeyde $31.40 \mathrm{~N} / \mathrm{mm}^{2}$, radyal yüzeyde $29.70 \mathrm{~N} / \mathrm{mm}^{2}$, enine yüzeyde $28.50 \mathrm{~N} / \mathrm{mm}^{2}$, eğilme direnci $94.30 \mathrm{~N} / \mathrm{mm}^{2}$, elastikiyet modülü $8069.00 \mathrm{~N} / \mathrm{mm}^{2}$, şok direnci $0.210 \mathrm{kgm} / \mathrm{cm}^{2}$ (Efe, 2021), janka sertlik değeri direnci teğet yüzeyde $27.21 \mathrm{~N} / \mathrm{mm}^{2}$, radyal yüzeyde $27.45 \mathrm{~N} / \mathrm{mm}^{2}$, enine yüzeyde $54.38 \mathrm{~N} / \mathrm{mm}^{2}$ (Ayata ve ark., 2018), 1s1 iletkenlik değeri $0.127 \mathrm{k}(\mathrm{W} / \mathrm{mK})$ (Çavuş ve ark., 2019) ve 16 hafta süreyle toprak ortamına bırakılmasından sonra meydana gelen ağırlık kaybı \%12.32 (Ayata ve Bal, 2019) olarak bulunmuştur.

Bu çalışmada, Toros sediri odunu yüzeylerine endüstriyel uygulamalara göre UV sistem parke vernikleri uygulanmış olup elde edilen malzemeler üzerinde UV-B lambalarının bulunduğu yapay yaşlandırmaya maruz bırakılması ile meydana gelen yüzey değişiklikleri belirlenmiştir. Elde edilen bu sonuçların literatüre katkı sağlayacağı düşünülmektedir.

\section{Materyal ve Metot}

\subsection{Materyal}

\subsubsection{Ahşap malzemenin temin edilmesi}


Toros sediri (Cedrus libani A. Rich) odunları İzmir'de bir kereste şirketinden satın alma yöntemiyle elde edilmiştir. Malzemeler mantar ve böcek kusuru olmayan, lif kıvrıklığı sorunu olmayan, ardaksız ve budaksız olacak şekilde rastgele olarak alınmıştır. 100 x 10 × $2 \mathrm{~cm}$ boyutlarında hazırlanmış 30 adet deney örneğine kesme ve rendeleme işlemi uygulanmıştır. Daha sonra malzemeler üzerinde iklimlendirme işlemleri yapılmıştır (TS 2471, 1976).

\subsection{Metot}

\subsubsection{UV sistem parke verniklerinin uygulaması}

$100 \mathrm{~cm} \times 10 \mathrm{~cm} \times 1.70 \mathrm{~cm}$ boyutlarında hazırlanmış olan Toros sediri odunlarına endüstriyel uygulamalara göre, KPS firması (Düzce, Türkiye) tarafından UV sistem vernikleri 3 ve 5 kat uygulanmıştır. UV sistem parke uygulama aşamaları Çizelge 1'de gösterilmiştir.

Çizelge 1. UV sistem parke verniği uygulaması

\begin{tabular}{|c|c|}
\hline 3 kat uygulaması & 5 kat uygulaması \\
\hline \multicolumn{2}{|c|}{ Kalibre zımpara uygulamas1 ( 80 ve 120 kum) } \\
\hline UV yüksek parlaklıkta perde kaplama (T9120-0900N1) $8 \mathrm{~g} / \mathrm{m}^{2}$ & UV şeffaf kürleşen sızdırmazlık macunu $(\mathrm{T} 9110-0000 \mathrm{H}) 20 \mathrm{~g} / \mathrm{m}^{2}\left(70^{\circ} \mathrm{C}\right)$ \\
\hline UV lamba kurutma uygulamasi $\left(177 \mathrm{~mJ} / \mathrm{cm}^{2}\right)(2 \mathrm{defa})$ & UV şeffaf kürleşen sızdırmazlık macunu (T9110-0000) $10 \mathrm{~g} / \mathrm{m}^{2}\left(170^{\circ} \mathrm{C}\right)(2 \mathrm{defa})$ \\
\hline \multicolumn{2}{|c|}{ Kalibre zımparalama işlemi (280 ve 320 kum) } \\
\hline \multicolumn{2}{|c|}{ Şeffaf mat UV yağı $(\mathrm{T} 9115-0000)\left(8 \mathrm{~g} / \mathrm{m}^{2}\right)$} \\
\hline \multicolumn{2}{|c|}{ UV lamba kurutma uygulamasi $\left(71 \mathrm{~mJ} / \mathrm{cm}^{2}\right)$} \\
\hline \multicolumn{2}{|c|}{ Şeffaf mat UV yăğ $(\mathrm{T} 9115-0000)\left(8 \mathrm{~g} / \mathrm{m}^{2}\right)$} \\
\hline \multicolumn{2}{|c|}{ UV lamba kurutma uygulaması $\left(314 \mathrm{~mJ} / \mathrm{cm}^{2}\right)(2 \mathrm{defa})$} \\
\hline
\end{tabular}

\subsubsection{Hızlandırılmış yaşlandırma uygulaması}

UV sistem parke verniği ( 3 ve 5 kat) uygulanan deney numunelerin yaşlandırılmasında, ISO 4892-3 (2016) standardına göre QUV hızlandırılmış yaşlandırma test cihazında (Q-Lab, Westlake, $\mathrm{OH}$, US) 0.76 1ş1k yoğunluğu ve $60^{\circ} \mathrm{C}$ 'de 8 saat UV 1şık; 4 saat $50^{\circ} \mathrm{C}$ sıcaklıkta kondenzasyon buhar yoğunlaştırma uygulaması ortamına sahip koşullar olacak şekilde ayarlanmıştır.

\subsubsection{Renk parametrelerinin belirlenmesi}

ASTM D2244-3 (2007) standardına göre, sarı renk $\left(b^{*}\right)$ tonu, kırmızı renk ( $\left.a^{*}\right)$ tonu ve 1şıklılık $\left(L^{*}\right)$ parametreleri 5 örnek üzerinde CS-10 (CHN Spec, Çin) marka renk ölçüm cihazında [CIE $10^{\circ}$ standart gözlemci; CIE D65 1şık kaynağı, aydınlatma sistemi: 8/d ( $8^{\circ}$ /dağınık aydınlatma)] belirlenmiştir. CIELAB sisteminde, $a^{*}$ kırmızı (+) ila yeşil (-) tonu, $L^{*}$ ekseni, 100'den (beyaz) sıfıra (siyah) kadar değişen açıklığı ve $b^{*}$ sarıdan (+) maviye (-) tonu olmaktadır (Gurleyen ve ark., 2017; Ayata, 2019, ). $\Delta a^{*}, \Delta b^{*}, \Delta L^{*}$ ve $\Delta E^{*}$ değerleri aşağıda verilen formüller ile hesaplanmıştır. Barański ve ark., (2017)'e göre renk değiştirme kriterleri Çizelge 2'de verilmiştir. Çizelge 2'ye göre de sonuçlar değerlendirilmiştir.

$$
\begin{aligned}
\Delta a^{*} & =\left[a^{*} \text { UV kürlenmeli vernik uygulanmıs ve yaşlandırılmış }\right]-\left[a^{*}\right. \text { UV kürlenmeli vernik uygulanmış ve yaşlandırılmamış] } \\
\Delta L^{*} & =\left[L^{*} \text { UV kürlenmeli vernik uygulanmış ve yaşlandırılmış }\right]-\left[L^{*} \text { UV kürlenmeli vernik uygulanmış ve yaşlandırılmamış }\right] \text { (2) } \\
\Delta b^{*} & =\left[b^{*} \text { UV kürlenmeli vernik uygulanmış ve yaşlandırılmış }\right]-\left[b^{*}\right. \text { UV kürlenmeli vernik uygulanmış ve yaşlandırılmamış] (3) } \\
\Delta E^{*} & =\left[\left(\Delta L^{*}\right)^{2}+\left(\Delta a^{*}\right)^{2}+\left(\Delta b^{*}\right)^{2}\right]^{1 / 2}
\end{aligned}
$$

Çizelge 2. Renk değiștirme kriterleri (Barański ve ark., 2017)

\begin{tabular}{ccc}
\hline $\boldsymbol{\Delta} \boldsymbol{E}^{*}$ Değeri & $\rightarrow$ & Gözlem Sonucu Verilen Kriter İ́adesi \\
\hline$\Delta E^{*}<0.2$ & $\rightarrow$ & Görünmez renk değişimi \\
$2>\Delta E^{*}>0.2$ & $\rightarrow$ & Hafif renk değişimi \\
$3>\Delta E^{*}>2$ & $\rightarrow$ & Yüksek filtrede görünür renk değişimi \\
$6>\Delta E^{*}>3$ & $\rightarrow$ & Filtrenin ortalama kalitesiyle görülebilen bir renk değişimi \\
$12>\Delta E^{*}>6$ & $\rightarrow$ & Yüksek renk değişimi \\
$\Delta E^{*}>12$ & $\rightarrow$ & Farklı renk \\
\hline
\end{tabular}




\subsubsection{Parlaklık ölçümlerinin belirlenmesi}

ETB-0833 model glossmeter cihazında (Vetus Electronic Technology Co., Ltd., CN) $20^{\circ}, 60^{\circ}$ ve $85^{\circ}$ de liflere paralel $(/ /)$ ve dik $(\perp)$ parlaklık ölçümleri ISO 2813 (1994) standardına göre belirlenmiştir.

\subsubsection{Yüzeye yapışma direncinin belirlenmesi}

ASTM D 4541 (1995) standardına göre ayarlanmış olan PosiTest AT-A (automatic) pull-off Adhesion Tester (Defelsko® crop., S/N AT11802, USA) cihazında yüzeye yapışma direnci testleri yapılmıştır. Hızlı yapıştırıcı olarak 404 Plastik Çelik marka (Çekmeköy/İstanbul) (reçine ve katalizör) kullanılmıştır. Vernikli malzemelerin yüzeyler 20 $\mathrm{mm}$ olan çekme silindirleri normal oda sıcaklığında $20^{\circ} \mathrm{C} \pm 2$ yapıştırılmıştır. Daha sonra, 24 saat süreyle kurumaya bırakılmıştır. 5 no'lu formül ile yapışma direnci hesaplanmıştır [F: kopma anındaki kuvvet (Newton), X: yapışma direnci (MPa) ve D: çekme silindirinin çapı $(\mathrm{mm})]$.

$$
\mathrm{X}=\left[(4 \times \mathrm{F}) /\left(\pi \mathrm{x} \mathrm{d}^{2}\right)\right]
$$

\subsubsection{Salınımsal sertlik değerinin belirlenmesi}

ASTM D 4366-95 (1984)'e standardı kullanılarak salınımsal sertlik testi König metoduna göre numuneler üzerinde yapılmıştır. Sertlik cihazı, HRC sertliğinde $63 \pm 3.3$ ve 5 $\pm 0.0005 \mathrm{~mm}$ çapında iki adet bilyeye sahip olmaktadır.

\subsection{7. İstatistiksel analiz}

Bu çalışmada, bir SPSS programı kullanılarak yapılan testlere ait homojenlik grupları, minimum ve maksimum değerler, standart sapmalar, ortalamaları ve varyans analizleri hesaplanmıştır.

\section{Bulgular ve Tartışma}

Yaşlandırılma testi sonrasında elde edilen 3 ve 5 kat UV sistem parke verniklerine ait katmanların toplam renk farklarına ait sonuçları Çizelge 3'de verilmiştir. Bu sonuçlara göre, Barański ve ark., (2017) kategorisine ait tablo dikkate alındığında 3 kat uygulamada yaşlandırma sonralarında "farklı renk" kategorisini verirken, 5 kat uygulaması için 252. saatin sonunda yüksek değişimi kategorisini verirken, 504 saatin sonunda "farklı renk" kategorisini verdiği görülmüştür. Her iki uygulamada yaşlandırma süresi ile $\Delta E^{*}$ değerlerinin arttığ görülmektedir. Buna benzer sonuçlar, Çavuş (2021) ve Ayata ve ark., (2021a) tarafından yapılan çalışmalarda da görülmüştür.

Renk parametreleri için belirlenmiş olan varyans analizinin sonuçları Çizelge 4'de verilmiştir. $\mathrm{Bu}$ sonuçlara göre, $L^{*}, a^{*}$ ve $b^{*}$ parametreleri için uygulama metodu (A), yaşlandırma periyodu (B) ve etkileşim (AB) anlamlı olarak belirlenmiştir (Çizelge 4).

Renk parametreleri $\left(L^{*}, a^{*}\right.$ ve $\left.b^{*}\right)$ için belirlenmiş olan SPSS sonuçları Çizelge 5'de verilmiştir. 3 ve 5 katmanlı UV sistemli malzemelerin $L^{*}, a^{*}$ ve $b^{*}$ değerleri sirasılyla, $L^{*}=$ 68.04 ve $70.67, a^{*}=10.92$ ve 9.26 ve $b^{*}=26.91$ ve 26.51 olarak belirlenmiştir. Yaşlandırma öncesi bu değerlerinin birbirlerine çok yakın olduğu görülmektedir. Yaşlandırmadan sonra $L^{*}$ değerleri azalmış olunup, $a^{*}$ ve $b^{*}$ değerleri ise artmıştır (Can ve Sivrikaya, 2019). Buna benzer sonuçlar, Gürleyen (2020) ve Ayata (2019) tarafından yapılan çalışmalarda da bildirilmiştir. Söğütlü ve Sönmez (2006) çalışmalarında $L^{*}$ değerinde görülen "artışın daha açık renk", "azalışın ise koyulaşmanın" anlamını verdiğini bildirilmişlerdir. Her iki vernik uygulamasında da yaşlandırmadan sonra azalmalar olduğu için koyulaşmanın elde edildiği söylenebilir. 
Ayata ve ark., Mobilya ve Ahşap Malzeme Araştırmaları Dergisi, 4(2), 145-154

Çizelge 3. Toplam renk farklılıklarına ait sonuçlar

\begin{tabular}{|c|c|c|c|c|c|c|c|}
\hline $\begin{array}{l}\text { Uygulama } \\
\text { Metodu }\end{array}$ & Yaşlandırma Periyodu & \multicolumn{2}{|c|}{$\begin{array}{c}\text { Renk kriterine göre klyaslamalar } \\
\text { (Barański ve ark., 2017) }\end{array}$} & $\Delta \boldsymbol{E}^{*}$ & $\Delta \boldsymbol{L}^{*}$ & $\Delta a^{*}$ & $\Delta b^{*}$ \\
\hline \multirow[b]{2}{*}{ UV 3 kat } & 252.ci saatin sonunda & Farklı renk & $\Delta E^{*}>12$ & 16.92 & -9.98 & 7.44 & 11.41 \\
\hline & 504.ci saatin sonunda & Farklı renk & $\Delta E^{*}>12$ & 18.42 & -9.75 & 8.40 & 13.14 \\
\hline \multirow{2}{*}{ UV 5 kat } & 252.ci saatin sonunda & Yüksek renk değişimi & $12>\Delta E^{*}>6$ & 11.92 & -7.39 & 4.97 & 7.90 \\
\hline & 504.ci saatin sonunda & Farklı renk & $\Delta E^{*}>12$ & 15.57 & -11.53 & 7.21 & 7.44 \\
\hline
\end{tabular}

Çizelge 4. Renk parametreleri $\left(L^{*}, a^{*}\right.$ ve $\left.b^{*}\right)$ için varyans analizinin sonuçları

\begin{tabular}{|c|c|c|c|c|c|c|}
\hline Test & Varyans Kaynağı & Serbestlik Derecesi & Kareler Toplamı & Ortalama Kare & F Değeri & $\alpha \leq 0.05$ \\
\hline \multirow{5}{*}{$L^{*}$} & Uygulama Metodu (A) & 1 & 125.744 & 125.744 & 139.465 & $0.000^{*}$ \\
\hline & Yaşlandırma Periyodu (B) & 2 & 1282.820 & 641.410 & 711.397 & $0.000 *$ \\
\hline & Etkileşim (AB) & 2 & 48.285 & 24.142 & 26.777 & $0.000^{*}$ \\
\hline & Hata & 54 & 48.688 & 0.902 & & \\
\hline & Toplam & 60 & 238990.788 & & & \\
\hline \multirow{5}{*}{$a^{*}$} & Uygulama Metodu (A) & 1 & 124.589 & 124.589 & 638.796 & $0.000^{*}$ \\
\hline & Yaşlandırma Periyodu (B) & 2 & 679.431 & 339.715 & 1741.799 & $0.000^{*}$ \\
\hline & Etkileşim (AB) & 2 & 15.308 & 7.654 & 39.243 & $0.000 *$ \\
\hline & Hata & 54 & 10.532 & 0.195 & & \\
\hline & Toplam & 60 & 13901.315 & & & \\
\hline \multirow{5}{*}{$b^{*}$} & Uygulama Metodu (A) & 1 & 180.614 & 180.614 & 522.518 & $0.000^{*}$ \\
\hline & Yaşlandırma Periyodu (B) & 2 & 1330.081 & 665.040 & 1923.974 & $0.000 *$ \\
\hline & Etkileşim (AB) & 2 & 82.769 & 41.385 & 119.726 & $0.000 *$ \\
\hline & Hata & 54 & 18.666 & 0.346 & & \\
\hline & Toplam & 60 & 68374.830 & & & \\
\hline
\end{tabular}

Çizelge 5. Renk parametrelerine $\left(L^{*}, a^{*}\right.$ ve $\left.b^{*}\right)$ ait sonuçlar

\begin{tabular}{|c|c|c|c|c|c|c|c|c|c|c|}
\hline Test & Metot & Yaşlandırma & $\mathbf{N}$ & Ortalama & $H G$ & Değişim (\%) & $S S$ & Minimum & Maksimum & $\mathrm{COV}$ \\
\hline \multirow{6}{*}{$L^{*}$} & \multirow{3}{*}{$\begin{array}{c}3 \text { kat } \\
\text { UV vernik }\end{array}$} & Kontrol & 10 & 68.04 & B & - & 1.06 & 65.50 & 69.72 & 1.56 \\
\hline & & 252 saat & 10 & 58.06 & $\mathrm{E}^{* *}$ & $\downarrow 14.67$ & 0.11 & 57.91 & 58.23 & 0.19 \\
\hline & & 504 saat & 10 & 58.29 & $\mathrm{DE}$ & $\downarrow 14.33$ & 1.12 & 56.89 & 59.88 & 1.92 \\
\hline & \multirow{3}{*}{$\begin{array}{c}5 \text { kat } \\
\text { UV vernik }\end{array}$} & Kontrol & 10 & 70.67 & $\mathrm{~A}^{*}$ & - & 0.66 & 69.30 & 71.49 & 0.93 \\
\hline & & 252 saat & 10 & 63.28 & $\mathrm{C}$ & $\downarrow 10.46$ & 0.43 & 62.41 & 63.82 & 0.68 \\
\hline & & 504 saat & 10 & 59.14 & D & $\downarrow 16.32$ & 1.55 & 55.98 & 61.17 & 2.62 \\
\hline \multirow{6}{*}{$a^{*}$} & \multirow{3}{*}{$\begin{array}{c}3 \text { kat } \\
\text { UV vernik }\end{array}$} & Kontrol & 10 & 10.92 & $\mathrm{E}$ & - & 0.47 & 10.04 & 11.89 & 4.30 \\
\hline & & 252 saat & 10 & 18.36 & B & $\uparrow 68.13$ & 0.16 & 18.05 & 18.59 & 0.87 \\
\hline & & 504 saat & 10 & 19.32 & A* & $\uparrow 76.92$ & 0.70 & 18.41 & 20.24 & 3.62 \\
\hline & \multirow{3}{*}{$\begin{array}{c}5 \text { kat } \\
\text { UV vernik }\end{array}$} & Kontrol & 10 & 9.26 & $\mathrm{~F}^{* *}$ & - & 0.22 & 9.00 & 9.71 & 2.38 \\
\hline & & 252 saat & 10 & 14.23 & $\mathrm{D}$ & $\uparrow 53.67$ & 0.22 & 13.95 & 14.73 & 1.55 \\
\hline & & 504 saat & 10 & 16.47 & $\mathrm{C}$ & $\uparrow 77.86$ & 0.58 & 15.53 & 17.59 & 3.52 \\
\hline \multirow{6}{*}{$b^{*}$} & \multirow{3}{*}{$\begin{array}{c}3 \text { kat } \\
\text { UV vernik }\end{array}$} & Kontrol & 10 & 26.91 & $\mathrm{D}$ & - & 0.28 & 26.45 & 27.22 & 1.04 \\
\hline & & 252 saat & 10 & 38.32 & B & $\uparrow 42.40$ & 0.44 & 37.58 & 38.94 & 1.15 \\
\hline & & 504 saat & 10 & 40.05 & A* & $\uparrow 48.83$ & 0.86 & 39.04 & 41.26 & 2.15 \\
\hline & \multirow{3}{*}{$\begin{array}{c}5 \text { kat } \\
\text { UV vernik }\end{array}$} & Kontrol & 10 & 26.51 & $\mathrm{D} * *$ & - & 0.53 & 25.99 & 27.32 & 2.00 \\
\hline & & 252 saat & 10 & 34.41 & $\mathrm{C}$ & $\uparrow 29.80$ & 0.35 & 33.67 & 34.95 & 1.02 \\
\hline & & 504 saat & 10 & 33.95 & $\mathrm{C}$ & $\uparrow 28.06$ & 0.81 & 32.49 & 35.50 & 2.39 \\
\hline
\end{tabular}

Çizelge 6 parlaklık ölçümleri için belirlenmiş olan varyans analizi sonuçlarını vermektedir. $\mathrm{Bu}$ sonuçlara göre, $20^{\circ}, 60^{\circ}$ ve $85^{\circ}$ 'de liflere paralel ve dik olarak yapilan parlaklık değerleri için uygulama metodu (A), yaşlandırma periyodu (B) ve bu faktörlerin (AB) etkileşimi anlamlı olarak belirlenmiştir.

UV sistem parke verniğine (3 ve 5 kat) sahip deney örneklerinin parlaklık ölçümlerine ait istatistiksel sonuçları Çizelge 7'de gösterilmektedir. Elde edilen sonuçlara göre, her iki vernik uygulaması için liflere dik ve paralel yönleri üzerinde ölçülen $20^{\circ}$ ve $60^{\circ}$ 'de parlaklık değerlerinin yaşlandırma uygulaması ile azaldığı görülmektedir. Buna ek olarak, 3 kat uygulamaya sahip örnekler de her iki ölçüm yönü için $85^{\circ}$ 'de parlaklık değerlerinin 252 saatlik yapay yaşlandırma ile arttığı, 504 saatlik yaşlandırma ile azaldığı belirlenirken, 5 kat uygulamaya sahip örnekler de ise yapay yaşlandırma süresinin artması ile azaldığı elde edilmiştir. 5 kat uygulamanın parlaklık değerleri 3 kat uygulamanınkinden yüksek elde edilmiştir. 
Çizelge 6. Parlaklık değerlerine ait varyans analizi sonuçları

\begin{tabular}{|c|c|c|c|c|c|c|}
\hline Test & Varyans Kaynağı & Serbestlik Derecesi & Kareler Toplamı & Ortalama Kare & F Değeri & $\alpha \leq 0.05$ \\
\hline \multirow{5}{*}{$/ / 20^{\circ}$} & Uygulama Metodu (A) & 1 & 11.882 & 11.882 & 662.127 & $0.000^{*}$ \\
\hline & Yașlandırma Periyodu (B) & 2 & 2.422 & 1.211 & 67.495 & $0.000 *$ \\
\hline & Etkileşim (AB) & 2 & 0.157 & 0.078 & 4.375 & $0.017 *$ \\
\hline & Hata & 54 & 0.969 & 0.018 & & \\
\hline & Toplam & 60 & 71.690 & & & \\
\hline \multirow{5}{*}{$/ / 60^{\circ}$} & Uygulama Metodu (A) & 1 & 1189.931 & 1189.931 & 21109.151 & $0.000^{*}$ \\
\hline & Yaşlandırma Periyodu (B) & 2 & 248.539 & 124.270 & 2204.518 & $0.000 *$ \\
\hline & Etkileşim (AB) & 2 & 78.080 & 39.040 & 692.565 & $0.000 *$ \\
\hline & Hata & 54 & 3.044 & 0.056 & & \\
\hline & Toplam & 60 & 4994.320 & & & \\
\hline \multirow{5}{*}{$/ / \mathbf{8 5}^{\circ}$} & Uygulama Metodu (A) & 1 & 3809.660 & 3809.660 & 40000.321 & $0.000 *$ \\
\hline & Yaşlandırma Periyodu (B) & 2 & 713.887 & 356.944 & 3747.803 & $0.000 *$ \\
\hline & Etkileşim (AB) & 2 & 481.406 & 240.703 & 2527.313 & $0.000 *$ \\
\hline & Hata & 54 & 5.143 & 0.095 & & \\
\hline & Toplam & 60 & 14287.850 & & & \\
\hline \multirow{5}{*}{$\perp \mathbf{2 0}^{\circ}$} & Uygulama Metodu (A) & 1 & 14.603 & 14.603 & 2560.208 & $0.000^{*}$ \\
\hline & Yaşlandırma Periyodu (B) & 2 & 3.348 & 1.674 & 293.494 & $0.000 *$ \\
\hline & Etkileşim (AB) & 2 & 0.225 & 0.113 & 19.753 & $0.000^{*}$ \\
\hline & Hata & 54 & 0.308 & 0.006 & & \\
\hline & Toplam & 60 & 73.780 & & & \\
\hline \multirow{5}{*}{$\perp 60^{\circ}$} & Uygulama Metodu (A) & 1 & 999.600 & 999.600 & 67388.775 & $0.000^{*}$ \\
\hline & Yaşlandırma Periyodu (B) & 2 & 178.644 & 89.322 & 6021.719 & $0.000 *$ \\
\hline & Etkileşim (AB) & 2 & 45.460 & 22.730 & 1532.371 & $0.000 *$ \\
\hline & Hata & 54 & 0.801 & 0.015 & & \\
\hline & Toplam & 60 & 3884.510 & & & \\
\hline \multirow{5}{*}{$\perp \mathbf{8 5}^{\circ}$} & Uygulama Metodu (A) & 1 & 1852.593 & 1852.593 & 12289.927 & $0.000^{*}$ \\
\hline & Yaşlandırma Periyodu (B) & 2 & 249.070 & 124.535 & 826.155 & $0.000 *$ \\
\hline & Etkileşim (AB) & 2 & 245.614 & 122.807 & 814.691 & $0.000 *$ \\
\hline & Hata & 54 & 8.140 & 0.151 & & \\
\hline & Toplam & 60 & 6285.540 & & & \\
\hline \multicolumn{7}{|c|}{ *: Anlamlı } \\
\hline
\end{tabular}

Çizelge 7. Parlaklık değerlerine ait sonuçlar

\begin{tabular}{|c|c|c|c|c|c|c|c|c|c|c|}
\hline Test & Metot & Yașlandırma & $\mathbf{N}$ & Ortalama & $H G$ & Değişim (\%) & $S S$ & Minimum & Maksimum & $\mathrm{COV}$ \\
\hline \multirow{6}{*}{$/ / 20^{\circ}$} & \multirow{3}{*}{$\begin{array}{c}\text { kat } \\
\text { UV vernik }\end{array}$} & Kontrol & 10 & 0.73 & $\mathrm{C}$ & - & 0.07 & 0.70 & 0.90 & 9.59 \\
\hline & & 252 saat & 10 & 0.54 & $\mathrm{D}$ & $\downarrow 26.03$ & 0.10 & 0.40 & 0.60 & 18.52 \\
\hline & & 504 saat & 10 & 0.30 & $\mathrm{E}^{* *}$ & $\downarrow 58.90$ & 0.00 & 0.30 & 0.30 & 0.00 \\
\hline & \multirow{3}{*}{$\begin{array}{c}5 \text { kat } \\
\text { UV vernik }\end{array}$} & Kontrol & 10 & 1.74 & $\mathrm{~A}^{*}$ & - & 0.28 & 1.10 & 2.00 & 16.09 \\
\hline & & 252 saat & 10 & 1.30 & $\mathrm{~B}$ & $\downarrow 25.29$ & 0.12 & 1.20 & 1.60 & 9.23 \\
\hline & & 504 saat & 10 & 1.20 & $\mathrm{~B}$ & $\downarrow 31.03$ & 0.00 & 1.20 & 1.20 & 0.00 \\
\hline \multirow{6}{*}{$/ / 60^{\circ}$} & \multirow{3}{*}{$\begin{array}{c}3 \text { kat } \\
\text { UV vernik }\end{array}$} & Kontrol & 10 & 4.31 & $\mathrm{D}$ & - & 0.11 & 4.10 & 4.40 & 2.55 \\
\hline & & 252 saat & 10 & 3.21 & $\mathrm{E}$ & $\downarrow 25.52$ & 0.31 & 3.00 & 3.80 & 9.66 \\
\hline & & 504 saat & 10 & 1.95 & $\mathrm{~F}^{* *}$ & $\downarrow 54.76$ & 0.15 & 1.80 & 2.30 & 7.69 \\
\hline & \multirow{3}{*}{$\begin{array}{c}5 \text { kat } \\
\text { UV vernik }\end{array}$} & Kontrol & 10 & 16.44 & $\mathrm{~A}^{*}$ & - & 0.20 & 16.10 & 16.70 & 1.22 \\
\hline & & 252 saat & 10 & 10.63 & $\mathrm{~B}$ & $\downarrow 35.34$ & 0.20 & 10.30 & 10.90 & 1.88 \\
\hline & & 504 saat & 10 & 9.12 & $\mathrm{C}$ & $\downarrow 44.53$ & 0.36 & 8.70 & 9.90 & 3.95 \\
\hline \multirow{6}{*}{$/ / \mathbf{8 5}^{\circ}$} & \multirow{3}{*}{$\begin{array}{c}3 \text { kat } \\
\text { UV vernik }\end{array}$} & Kontrol & 10 & 3.63 & $E$ & - & 0.18 & 3.40 & 3.90 & 4.96 \\
\hline & & 252 saat & 10 & 7.45 & $\mathrm{D}$ & $\uparrow 105.23$ & 0.15 & 7.20 & 7.70 & 2.01 \\
\hline & & 504 saat & 10 & 2.32 & $\mathrm{~F}^{* *}$ & $\downarrow 36.09$ & 0.06 & 2.30 & 2.50 & 2.59 \\
\hline & \multirow{3}{*}{$\begin{array}{c}5 \text { kat } \\
\text { UV vernik }\end{array}$} & Kontrol & 10 & 27.41 & $\mathrm{~A}^{*}$ & - & 0.35 & 26.80 & 27.90 & 1.28 \\
\hline & & 252 saat & 10 & 20.88 & $\mathrm{~B}$ & $\downarrow 23.82$ & 0.36 & 20.50 & 21.60 & 1.72 \\
\hline & & 504 saat & 10 & 12.92 & $\mathrm{C}$ & $\downarrow 52.86$ & 0.51 & 11.90 & 13.50 & 3.95 \\
\hline \multirow{6}{*}{$\perp 20^{\circ}$} & \multirow{3}{*}{$\begin{array}{c}3 \text { kat } \\
\text { UV vernik }\end{array}$} & Kontrol & 10 & 0.71 & $\mathrm{D}$ & - & 0.03 & 0.70 & 0.80 & 4.23 \\
\hline & & 252 saat & 10 & 0.39 & $\mathrm{E}$ & $\downarrow 45.07$ & 0.09 & 0.30 & 0.50 & 23.08 \\
\hline & & 504 saat & 10 & 0.30 & $\mathrm{~F}^{* *}$ & $\downarrow 57.75$ & 0.00 & 0.30 & 0.30 & 0.00 \\
\hline & \multirow{3}{*}{$\begin{array}{c}5 \text { kat } \\
\text { UV vernik }\end{array}$} & Kontrol & 10 & 1.87 & $\mathrm{~A}^{*}$ & - & 0.09 & 1.60 & 1.90 & 4.81 \\
\hline & & 252 saat & 10 & 1.29 & B & $\downarrow 31.02$ & 0.13 & 1.20 & 1.60 & 10.08 \\
\hline & & 504 saat & 10 & 1.20 & $\mathrm{C}$ & $\downarrow 35.83$ & 0.00 & 1.20 & 1.20 & 0.00 \\
\hline \multirow{6}{*}{$\perp 60^{\circ}$} & \multirow{3}{*}{$\begin{array}{c}3 \text { kat } \\
\text { UV vernik }\end{array}$} & Kontrol & 10 & 3.73 & $\mathrm{D}$ & - & 0.11 & 3.60 & 3.90 & 2.95 \\
\hline & & 252 saat & 10 & 2.65 & $\mathrm{E}$ & $\downarrow 28.95$ & 0.05 & 2.60 & 2.70 & 1.89 \\
\hline & & 504 saat & 10 & 1.35 & $\mathrm{~F}^{* *}$ & $\downarrow 63.81$ & 0.07 & 1.30 & 1.50 & 5.19 \\
\hline & \multirow{3}{*}{$\begin{array}{c}5 \text { kat } \\
\text { UV vernik }\end{array}$} & Kontrol & 10 & 14.33 & $\mathrm{~A}^{*}$ & - & 0.09 & 14.20 & 14.40 & 0.63 \\
\hline & & 252 saat & 10 & 9.29 & B & $\downarrow 35.17$ & 0.11 & 9.10 & 9.50 & 1.18 \\
\hline & & 504 saat & 10 & 8.60 & $\mathrm{C}$ & $\downarrow 39.99$ & 0.22 & 8.20 & 8.90 & 2.56 \\
\hline \multirow{6}{*}{$\perp 85^{\circ}$} & \multirow{3}{*}{$\begin{array}{c}3 \text { kat } \\
\text { UV vernik }\end{array}$} & Kontrol & 10 & 1.87 & $E$ & - & 0.31 & 1.60 & 2.50 & 16.58 \\
\hline & & 252 saat & 10 & 4.31 & $\mathrm{D}$ & $\uparrow 130.48$ & 0.25 & 3.80 & 4.60 & 5.80 \\
\hline & & 504 saat & 10 & 1.43 & $\mathrm{~F}^{* *}$ & $\downarrow 23.53$ & 0.13 & 1.10 & 1.50 & 9.09 \\
\hline & \multirow{3}{*}{$\begin{array}{c}5 \text { kat } \\
\text { UV vernik }\end{array}$} & Kontrol & 10 & 18.69 & $\mathrm{~A}^{*}$ & - & 0.23 & 18.20 & 19.00 & 1.23 \\
\hline & & 252 saat & 10 & 12.94 & B & $\downarrow 30.77$ & 0.78 & 12.40 & 15.10 & 6.03 \\
\hline & & 504 saat & 10 & 9.32 & $\mathrm{C}$ & $\downarrow 50.13$ & 0.24 & 9.00 & 9.70 & 2.58 \\
\hline
\end{tabular}


Salınımsal sertlik değerine ve yüzeye yapışma direncine ait varyans analizi sonuçlarını Çizelge 8'de göstermektedir. Salınımsal sertlik değerinde uygulama metodu (A), yaşlandırma periyodu (B) ve etkileşim (AB) anlamlı olarak elde edilmiştir. Yüzeye yapışma direncinde ise uygulama metodu (A) anlamsız elde edilirken, yaşlandırma periyodu (B) ve etkileşim (AB) anlamlı olarak belirlenmiştir (Çizelge 8).

Yaşlandırma öncesi ve sonralarında belirlenmiş olan salınımsal sertlik değeri ve yüzeye yapışma direnci için sonuçları Çizelge 9'da gösterilmektedir. Salınımsal sertlik direnci 3 kat uygulanmış deney örneklerinde yaşlandırma sonralarında azalma verirken, 5 kat uygulanmış örnekler üzerinde artış göstermiştir. Buna benzer sonuçlar, Gürleyen (2020), (2021) ve Ayata ve ark., (2021a,b) çalışmalarda da rapor edilmiştir. Ayrıca her iki vernik uygulaması için kontrol örnekleri birbirine çok yakın sonuçlar vermiştir. Yüzeye yapışma direncinde ise, her iki vernik türünde 252 saatlik yaşlandırma sonralarında önce azalma elde edilirken, 504 saatlik yaşlandırma sonunda ise artış belirlenmiştir. 5 kat uygulamanın kontrol sonucu, 3 kat uygulamanınkinden yüksek elde edilmiştir.

Çizelge 8. Salınımsal sertlik değeri ve yüzeye yapışma direnci için varyans analizi sonuçları

\begin{tabular}{|c|c|c|c|c|c|c|}
\hline Test & Varyans Kaynağı & Serbestlik Derecesi & Kareler Toplamı & Ortalama Kare & F Değeri & $\alpha \leq 0.05$ \\
\hline \multirow{5}{*}{$\begin{array}{l}\text { Salınımsal } \\
\text { Sertlik }\end{array}$} & Uygulama Metodu (A) & 1 & 1792.111 & 1792.111 & 253.601 & $0.000^{*}$ \\
\hline & Yaşlandırma Periyodu (B) & 2 & 655.056 & 327.528 & 46.348 & $0.000^{*}$ \\
\hline & Etkileşim (AB) & 2 & 1045.056 & 522.528 & 73.943 & $0.000^{*}$ \\
\hline & Hata & 30 & 212.000 & 7.067 & & \\
\hline & Toplam & 36 & 55082.000 & & & \\
\hline & Uygulama Metodu (A) & 1 & 0.028 & 0.028 & 2.611 & $0.119 * *$ \\
\hline Yüzeye & Yaşlandırma Periyodu (B) & 2 & 2.658 & 1.329 & 122.984 & $0.000 *$ \\
\hline Yapışma & Etkileşim (AB) & 2 & 0.245 & 0.123 & 11.349 & $0.000^{*}$ \\
\hline \multirow[t]{2}{*}{ Direnci } & Hata & 24 & 0.259 & 0.011 & & \\
\hline & Toplam & 30 & 55.992 & & & \\
\hline \multicolumn{7}{|c|}{ *: Anlamlı } \\
\hline
\end{tabular}

Çizelge 9. Salınımsal sertlik değeri ve yüzeye yapışma direnci için sonuçlar

\begin{tabular}{|c|c|c|c|c|c|c|c|c|c|c|}
\hline Test & Metot & Yaşlandırma & $\mathbf{N}$ & Ortalama & $H G$ & Değişim (\%) & $S S$ & Minimum & Maksimum & $\mathrm{COV}$ \\
\hline \multirow{6}{*}{$\begin{array}{l}\text { Salınımsal } \\
\text { Sertlik }\end{array}$} & \multirow{3}{*}{$\begin{array}{c}3 \text { kat } \\
\text { UV vernik }\end{array}$} & Kontrol & 6 & 32.17 & $\mathrm{~B}$ & - & 2.93 & 29.00 & 36.00 & 9.11 \\
\hline & & 252 saat & 6 & 28.50 & $\mathrm{C}^{* *}$ & $\downarrow 11.41$ & 2.43 & 26.00 & 33.00 & 8.53 \\
\hline & & 504 saat & 6 & 31.50 & $\mathrm{BC}$ & $\downarrow 2.08$ & 2.66 & 27.00 & 35.00 & 8.44 \\
\hline & \multirow{3}{*}{$\begin{array}{c}5 \text { kat } \\
\text { UV vernik }\end{array}$} & Kontrol & 6 & 31.33 & $\mathrm{BC}$ & - & 1.63 & 29.00 & 33.00 & 5.20 \\
\hline & & 252 saat & 6 & 52.67 & A* & $\uparrow 68.11$ & 3.50 & 47.00 & 57.00 & 6.65 \\
\hline & & 504 saat & 6 & 50.50 & $\mathrm{~A}$ & $\uparrow 61.19$ & 2.43 & 47.00 & 54.00 & 4.81 \\
\hline \multirow{6}{*}{$\begin{array}{c}\text { Yüzeye } \\
\text { Yapışma } \\
\text { Direnci } \\
\text { (MPa) }\end{array}$} & \multirow{3}{*}{$\begin{array}{c}3 \text { kat } \\
\text { UV vernik }\end{array}$} & Kontrol & 5 & 1.622 & B & - & 0.14 & 1.480 & 1.820 & 8.63 \\
\hline & & 252 saat & 5 & 1.116 & D & $\downarrow 31.20$ & 0.09 & 1.020 & 1.260 & 8.06 \\
\hline & & 504 saat & 5 & 1.334 & $\mathrm{C}$ & $\uparrow 17.76$ & 0.06 & 1.270 & 1.430 & 4.50 \\
\hline & \multirow{3}{*}{$\begin{array}{c}5 \text { kat } \\
\text { UV vernik }\end{array}$} & Kontrol & 5 & 1.790 & $\mathrm{~A}^{*}$ & - & 0.10 & 1.620 & 1.860 & 5.59 \\
\hline & & 252 saat & 5 & 0.842 & $\mathrm{E}^{* *}$ & $\downarrow 52.96$ & 0.07 & 0.740 & 0.910 & 8.31 \\
\hline & & 504 saat & 5 & 1.256 & $\mathrm{C}$ & $\uparrow 29.83$ & 0.14 & 1.110 & 1.410 & 11.15 \\
\hline
\end{tabular}

\section{Sonuçlar ve Öneriler}

UV kürlenmeli vernikler kaplanmış malzemeler üzerindeki yaşlandırma sonrası yaşanan değişiklikler, çevre ortamına ait iklim şartlarının oluşumuna bağlıdır. Bu çalışmada elde edilen sonuçlar, yapay yaşlandırma uygulanan kaplama türü ile kullanılan ağaç türü arasındaki ilişkinin durumuna açıklık getirmiştir.

- UV kürlenmeli vernikler kullanılarak iki farklı uygulama yöntemi ile kaplanmış sedir odununda yaşlandırma uygulamaları, parlaklık değerlerinde ve 1şılılık değerlerinde azalmalara, kırmızı ve sarı renk tonlarında ise artışa sebep olmuştur.

- Sonuç olarak, literatürdeki çalışmalarla bu çalışma kıyaslandığında Toros sedirinin UV parke endüstrisinde kullanılan bileceği söylenebilir.

- Bu malzemelerin başka yaşlandırma uygulamaları ile muamele edilmesi ve çeşitli testler ile elde edilecek sonuçların kıyaslanması önerilmektedir. 


\section{Teşekkür}

UV sistem parke verniğine ait uygulamalar için KPS Fabrikası'na (Düzce) yazarlar teşekkür etmektedir.

\section{Yazar Katkıları}

Ümit AYATA: Laboratuvar çalışmalarının yapılması, verilerin elde edilmesi, makalenin yazılması, Nevzat ÇAKICIER: Laboratuvar çalışmalarının yapılması, Levent GÜRLEYEN: Laboratuvar çalışmalarının yapılması.

\section{Kaynaklar}

ASTM D 2244-3, (2007), Standard practice for calculation or color tolerances and color, differences from instrumentally measured color coordinates, ASTM International, West Conshohocken, PA.

ASTM D 4366-95, (1984), Standard test methods for hardness of organic coatings by pendulum test, ASTM, Philadelphia, PA.

ASTM D 4541, (1995), Standard test method for pull-off strength of coatings using portable adhesion testers, ASTM International, West Conshohocken, PA.

Ayata, Ü. (2019), Effects of artificial weathering on the surface properties of ultraviolet varnish applied to lemonwood (Citrus limon (L.) Burm.), Bioresources, 14(4), 83138323. DOI: 10.15376/biores.14.4.8313-8323.

Ayata, Ü., Bal, B. C. (2019), Mikrobiyolojik olarak aktif olan toprağa maruz kalmış Toros sediri (Cedrus libani A. Rich.) odununda 1s1l işlemin etkisi, Avrasya 4. Uluslararas1 Uygulamalı Bilimler Kongresi, 27-29 Eylül, Kiev, Ukrayna, 13-18.

Ayata, Ü., Çavuş, V., Bal, B. C., Efe, F. T. (2018), Dut, doğu çınarı, kızılçam ve sedir ağaç türlerinde janka sertlik değerinin belirlenmesi, 2. Uluslararası Bilimsel Çalışmalarda Yenilikçi Yaklaşımlar Sempozyumu, 30 Kasım - 2 Aralık, Samsun, Türkiye, 14901494.

Ayata, Ü., Çakıcıer, N., Gürleyen, L. (2021a), İç mekânda kullanılan UV sistem parke verniği uygulamasına sahip kayısı odununda yapay yaşlandırma performansının belirlenmesi, Mobilya ve Ahşap Malzeme Araştırmaları Dergisi, 4(1), 40-50. DOI: 10.33725/mamad. 922311.

Ayata, Ü., Esteves, B., Gürleyen, L., Çakıcıer, N., Ferreira, J., Domingos, I., Türk, M. (2021b), Effect of accelerated ageing on some surface properties of UV-coated hackberry (Celtis australis L.) wood parquet, Drevno, 64(208). DOI: 10.12841/wood.1644-3985.383.09.

Barański, J., Klement, I., Vilkovská, T., Konopka, A. (2017), High temperature drying process of beech wood (Fagus sylvatica L.) with different zones of sapwood and red false heartwood, BioResources, 12(1), 1861-1870. DOI: 10.15376/biores.12.1.18611870 .

Bruen, K., Davidson, K., Sydes, D. F. E., Peter, M. (2004), Benefits of UV-curable coatings, European Coatings Journal, 4, 42-48.

Can, A. (2018), Su itici maddeler ile kombine edilmiş bazı emprenye maddelerinin performansının incelenmesi, Bartın Üniversitesi, Fen Bilimleri Enstitüsü, Doktora tezi. 
Can, A., Sivrikaya, H. (2019), Surface characterization of wood treated with boron compounds combined with water repellents, Color Research \& Application, 44(3), 462472. DOI: $10.1002 / \mathrm{col} .22357$.

Cavus V., Sahin S., Esteves B., Ayata U. (2019), Determination of thermal conductivity properties in some wood species obtained from Turkey, Bioresources, 14(3), 67096715. DOI: 10.15376/biores.14.3.6709-6715.

Çavuş, V. (2021), Weathering performance of mulberry wood with UV varnish applied and its mechanical properties, BioResources, 16(4), 6791-6798. DOI: 10.15376/biores.16.4.6791-6798.

Chiang, W., Chan, S. (1987), Preparation and properties of photocurable unsaturated oligoester acrylourethanes, Journal of Applied Polymer Science, 34(1), 127-141. DOI: 10.1002/app.1987.070340111.

Dutkuner İ., Akten M. (2000), Kahramanmaraş’ta kent içi park ve ağaçlandırmalarda kullanılabilecek ağaç taksonları, KSÜ, Fen ve Mühendislik Dergisi, 3(1-2), 28-35.

Efe, F. T. (2021), Sedir odununun bazı fiziksel ve mekanik özelliklerinin belirlenmesi üzerine bir araştırma, Türk Tarım ve Doğa Bilimleri Dergisi, 8(1), 43-52. DOI: 10.30910/turkjans.809010.

Evans, P. D., Thay, P. D., Schmalzl, K. J. (1996), Degradation of wood surfaces during natural weathering, Effects on lignin and cellulose and on the adhesion of acrylic latex primers, Wood Science and Technology, 30, 411-422.

Gheno, G., Ganzerla, R., Bortoluzzi, M., Paganica, R. (2016), Accelerated weathering degradation behaviour of polyester thermosetting powder coatings, Progress in Organic Coatings, 101, 90-99. DOI: 10.1016/j.porgcoat.2016.07.004.

Gürleyen, L. (2020), UV sistem parke verniği uygulanmış gülibrişim (Albizia julibrissin) odununda bazı yüzey özellikleri üzerine yapay yaşlandırmanın etkisi, Türkiye Ormancllık Dergisi, 21(4), 451-460. DOI: 10.18182/tjf.795597.

Gurleyen, L. (2021), Effects of artificial weathering on the color, gloss, adhesion, and pendulum hardness of UV system parquet varnish applied to doussie (Afzelia africana) wood, BioResources, 16(1), 1616-1627. DOI: 10.15376/biores.16.1.1616-1627.

Gurleyen, T., Ayata, U., Gurleyen, L., Esteves, B., Sivrikaya, H., Can, A. (2017), The determination of colour and glossiness properties on santos, rose and rowan woods heat treated according to ThermoWood method, 2nd International Conference on Material Science and Technology in Cappadocia (IMSTEC'17), October 11-13, 2017, Nevsehir/Turkey, 401-407.

Hon, D. N. -S. (2001), Weathering and photochemistry of wood, In: Hon DN-S, Shiraishi, N., (eds) Wood and cellulose chemistry, Marcel Dekker, New York, pp 513-546.

ISO 2813, (1994), Paints and varnishes - determination of specular gloss of non-metallic paint films at 20 degrees, 60 degrees and 85 degrees, International Organization for Standardization, Geneva, Switzerland.

ISO 4892-3, (2016), Plastics - Methods of exposure to laboratory light sources - Part 3: Fluorescent UV lamps, The International Organization for Standardization. 
Kilambi, H., Reddy, S. K., Schneidewind, L., Stansbury, J. W., Bowman, C. N. (2014), Copolymerization and dark polymerization studies for photopolymerization of novel acrylic monomers, Polymers, 48(7), 2014-2021. DOI: 10.1016/j.polymer.2007.02.006.

Liu, F., Liu, A., Tao, W., Yang, Y. (2020), Preparation of UV curable organic/inorganic hybrid coatings-a review, Progress in Organic Coatings, 145, 105685. DOI: 10.1016/j.porgcoat.2020.105685.

Pedrón, S., Bosch, P., Peinado, C. (2008), Using hyper branched macromers as cross linkers of meth acrylic networks prepared by photo polymerization, Journal of Photochemistry and Photobiology A: Chemistry, 200(2-3), 126-140, DOI: 10.1016/j.jphotochem. 2008.07.002.

Rogers, S. O., Kaya, Z. (2006), DNA from ancient cedar wood from King Midas Tomb, Turkey, and Al-Aksa Mosque, Israel, Silvae Genetica, 55(2), 54-62. DOI: 10.1515/sg2006-0009.

Söğütlü, C., Sönmez, A. (2006), Değişik koruyucular ile işlem görmüş bazı yerli ağaçlarda UV ışınlarının renk değiştirici etkisi, Gazi Üniversitesi, Mühendislik Mimarlık Fakültesi Dergisi, 21(1), 151-159.

TS 2471, (1976), Odunda, fiziksel ve mekaniksel deneyler için rutubet miktarı tayini, Türk Standartları Enstitüsü, Ankara.

Wicks, Z. W. (2007), Organic Coatings: Science and Technology, third ed., WileyInterscience, Hoboken, NJ, 574-584. 